\title{
A combination of transcriptome and methylation analyses reveals embryologically-relevant candidate genes in MRKH patients
}

\author{
Katharina Rall ${ }^{1 *}$, Gianmaria Barresi ${ }^{1}$, Michael Walter $^{2}$, Sven Poths ${ }^{2}$, Karina Haebig ${ }^{2}$, Karin Schaeferhoff ${ }^{2}$, \\ Birgitt Schoenfisch?', Olaf Riess ${ }^{2}$, Diethelm Wallwiener ${ }^{1}$, Michael Bonin ${ }^{2+}$ and Sara Brucker ${ }^{1+}$
}

\begin{abstract}
Background: The Mayer-Rokitansky-Küster-Hauser (MRKH) syndrome is present in at least 1 out of 4,500 female live births and is the second most common cause for primary amenorrhea. It is characterized by vaginal and uterine aplasia in an XX individual with normal secondary characteristics. It has long been considered a sporadic anomaly, but familial clustering occurs. Several candidate genes have been studied although no single factor has yet been identified. Cases of discordant monozygotic twins suggest that the involvement of epigenetic factors is more likely.

Methods: Differences in gene expression and methylation patterns of uterine tissue between eight MRKH patients and eight controls were identified using whole-genome microarray analyses. Results obtained by expression and methylation arrays were confirmed by qRT-PCR and pyrosequencing.

Results: We delineated 293 differentially expressed and 194 differentially methylated genes of which nine overlap in both groups. These nine genes are mainly embryologically relevant for the development of the female genital tract.

Conclusion: Our study used, for the first time, a combined whole-genome expression and methylation approach to reveal the etiology of the MRKH syndrome. The findings suggest that either deficient estrogen receptors or the ectopic expression of certain HOXA genes might lead to abnormal development of the female reproductive tract. In utero exposure to endocrine disruptors or abnormally high maternal hormone levels might cause ectopic expression or anterior transformation of HOXA genes. It is, however, also possible that different factors influence the anti-Mullerian hormone promoter activity during embryological development causing regression of the Müllerian ducts. Thus, our data stimulate new research directions to decipher the pathogenic basis of MRKH syndrome.
\end{abstract}

\section{Background}

The Mayer-Rokitansky-Küster-Hauser (MRKH) syndrome (OMIM 277000) is the second most common cause of primary amenorrhea and affects at least 1 in 4,500 females. It is characterized by congenital absence of the uterus and the upper two thirds of the vagina in women with a normal female karyotype. As the ovaries are functional, women affected have physiological hormone levels and normal secondary sexual characteristics [1]. The MRKH syndrome may occur isolated (type I),

\footnotetext{
* Correspondence: Katharina.Rall@med.uni-tuebingen.de

+ Contributed equally

'University Hospital Tuebingen, Department of Obstetrics and Gynecology,

Tuebingen, Germany

Full list of author information is available at the end of the article
}

or can be associated with renal or skeletal malformations, and, to a lesser extent, auditory and cardiac defects (type II) [2]. Although it is generally sporadic, familial clustering has been described, indicating a genetic cause [3]. Familial cases have been explained by autosomal dominant inheritance with incomplete penetrance and variable expressivity or by small chromosomal aberrations undetectable in standard karyotypes [4]. However, the lack of families with informative genetic histories has not allowed the identification of any locus using standard genetic linkage analysis. Investigations have therefore used a candidate gene approach based on association with other genetic diseases or involvement during embryogenesis [4].

\section{Biomed Central}


The association of abnormalities in Müllerian duct (MD) development with renal, skeletal, cardiac and auditory defects suggests that crucial genes of fetal development and sex differentiation such as HOX, WNT and those encoding anti-Müllerian hormone $(\mathrm{AMH})$ and its receptor are potential candidates $[5,6]$. The WNT genes control the production of a large family of proteins involved in intercellular signaling during embryogenesis. Heterozygous mutations of WNT4 have been detected in a subgroup of patients, but these patients also show signs of hyperandrogenism [7-10]. HOX genes play key roles in body patterning and organogenesis, in particular during genital tract development and the differentiation of the kidneys and skeleton. Thus, expression or function defects in one or several $H O X$ genes may account for this syndrome. Furthermore, several hormones regulate physiological processes in the adult female reproductive tract by regulating $H O X$ gene expression. Alterations in $H O X$ gene expression that persist in the adult are a molecular mechanism by which endocrine disruptors may affect reproductive tract development $[11,12]$. However, structural abnormalities in $H O X$ genes or in hormones regulating $H O X$ expression have not been identified in women with MRKH syndrome until today [13-17]. As a third group of genes, $\mathrm{AMH}$ and its receptor have been regarded as causative factors in MRKH syndrome as AMH initiates MD regression in the 6th gestational week [18-22]. Mutation analyses of the $A M H$ gene, however, did not support a link between MRKH syndrome and AMH yet $[18,23]$. Finally, mutations in other genes with a broad spectrum of activity during early development such as WT1, PAX2 and others have also been excluded in MRKH patients [4].

From the previous studies one can conclude that the targeted candidate gene approach has failed to decipher the causes of MRKH syndrome [2,5,24]. Recently, several recurrent copy number variants in patients with isolated and syndromic Müllerian aplasia have been described, but none of them was consistently found in a larger group of patients [25].

Cases of discordant monozygotic twins suggest that the involvement of epigenetic factors is more likely. Several studies have identified epigenetic differences, either for selected genes in monozygotic twins or in the overall epigenome [26,27].

We provide here the first study using a whole-genome approach to detect differences at the transcriptome and methylome level between MRKH patients and healthy controls. As integrated genomics becomes more and more important, the synergy between transcriptional and epigenetic gene regulation may be used to better understand the etiology of MRKH syndrome.

\section{Methods}

\section{Patients}

This study was approved by the ethics committee of the Eberhard-Karls-University of Tuebingen. Between July 2007 and December 2010, we had partly or completely excised 102 rudimentary uterine structures during laparoscopic-assisted neovagina in MRKH patients after informed consent was obtained [28]. As controls, we included 63 patients who underwent hysterectomy for benign disease in the same period.

Microarray analysis was performed in eight patients and eight controls to detect differentially expressed genes and seven patients and seven controls from the same group to detect differentially methylated CpG sites. Of these patients, four had MRKH type I and four had MRKH type II, including three patients with skeletal malformations, and amongst these, one with Fallot's tetralogy and one with ureter abnormalities. None of the patients had MURCS association or other complex malformations.

Analysis of serum samples at the time of surgery showed similar distribution between cycle phase one and two in the patients and control group.

Tissue samples were examined histologically before RNA and DNA were isolated. All tissue samples in both groups consisted of more than $80 \%$ myometrium.

\section{RNA and DNA isolation}

The total RNA from myometrial pieces of rudimentary uterine tissue or normal uterus was isolated using the RNeasy ${ }^{\circledR}$ Mini Kit (Qiagen, Hilden, Germany). RNA quality was checked by a Lab-on-a-Chip-System Bioanalyzer 2100 (Agilent, Boeblingen, Germany), and the concentration was determined using a BioPhotometer (Eppendorf, Hamburg, Germany). DNA was isolated using the DNeasy ${ }^{\circledR}$ purification Kit (Qiagen, Hilden, Germany) according to protocol and the concentration was determined using a BioPhotometer (Eppendorf).

\section{Affymetrix microarray analysis}

Double-stranded cDNA was synthesized from $100 \mathrm{ng}$ of total RNA and subsequently linearly amplified and biotinylated using the GeneChip ${ }^{\circledR}$ WT cDNA Synthesis and Amplification Kit (Affymetrix, Santa Clara, CA, USA) according to the manufacturer's instructions. $15 \mu \mathrm{g}$ of labeled and fragmented cDNA was hybridized to GeneChip ${ }^{\circledR}$ Human Gene 1.0 ST arrays (Affymetrix). Arrays were scanned using the GCS3000 Gene Chip scanner (Affymetrix) and AGCC 3.0 software. Scanned images were inspected visually to check for hybridization artifacts and proper grid alignment and analyzed with Expression Console 1.0 (Affymetrix) to generate report files for quality control. 


\section{Quantitative real-time PCR}

Relative expression of selected mRNA targets was determined by quantitative real-time PCR (qRT-PCR). 250$500 \mathrm{ng}$ of total RNA was reverse transcribed using a QuantiTect Reverse Transcription Kit (Qiagen) according to the manufacturer. cDNA was diluted 1:10 before PCR amplification or preamplified using the TaqMan PreAmp Master Mix Kit (Applied Biosystems, Carlsbad, CA, USA) according to the manufacturer's protocol and diluted 1:20 for the subsequent PCR analysis. Primers were designed with Primer3 or PrimerBlast (http://biotools.umassmed.edu/bioapps/primer3_www.cgi, http:// www.ncbi.nlm.nih.gov/tools/primer-blast/) and synthesized by Metabion (Metabion, Martinsried, Germany). Table 1 gives a list of PCR targets and primers.

Real-time detection of specific PCR products was performed on a LightCycler480 (Roche, Penzberg, Germany) with $5 \mu \mathrm{L}$ of $2 \mathrm{x}$ QuantiTect SYBR Green PCR Kit (Qiagen). The PCR reaction was initiated by a $10 \mathrm{~min}$ hot start followed by 45 cycles of $95^{\circ} \mathrm{C}$ for $20 \mathrm{~s}, 58^{\circ} \mathrm{C}$ for $40 \mathrm{~s}$, and $72^{\circ} \mathrm{C}$ for $20 \mathrm{~s}$. Each PCR reaction was performed in three technical replicates. PCR efficiency was calculated from 4or 5-fold serial dilutions of an equal mixture of all cDNAs using the following equation: $E=10^{\wedge}[-1 /$ slope] [29]. To calculate the relative expression of each target, the raw $\mathrm{Cp}$ values were imported into qBase [30]. Three suitable reference genes (PDH, SDHA, PGRMC1 or HISPPD1) were selected according to their $\mathrm{M}$-values and used for normalization of the qRT-PCR reactions [31,32].

\section{Illumina methylation array analysis}

200-500 ng DNA was bisulfite-converted using the EZ DNA Methylation Kit (Zymo Research, Orange, CA, USA) according to the manufacturer's protocol.
Seven patient and seven control probes were evaluated for genome-wide promoter methylation using the Illumina Infinium HumanMethylation27 BeadArray.

After bisulfite conversion, each sample was whole-genome amplified (WGA) and enzymatically fragmented. The bisulfite-converted WGA-DNA samples were purified and applied to the BeadChips. Allele-specific primer annealing is followed by single-base extension using DNP- and Biotin-labeled ddNTPs. DNA methylation values, described as beta values, are recorded for each locus in each sample via BeadStudio software [33].

Differential methylation was assessed by subtracting the mean methylation level (beta value) of the patient group from the mean beta value of the reference group using BeadStudio software.

\section{Pyrosequencing methylation analysis}

PCR and sequencing primer were designed by Qiagen using the PyroMark Assay Design Software 2.0 and are shown in Table 2. For each gene, we selected the sequence of the $\mathrm{CpG}$ island region which had previously been identified as differentially methylated in the array experiments. One to five adjacent CpG sites were analyzed for each $\mathrm{CpG}$ island. Five patient and five control samples were included in the experiment. $200 \mathrm{ng}$ of isolated DNA was bisulfite-converted using the EZ DNA Methylation Kit (Zymo). 24 ng of bisulfite-treated DNA were amplified in reaction mixture containing forward and reverse primer, $1 \mathrm{U}$ of HotStarTaq DNA Polymerase (Qiagen), $200 \mu \mathrm{mol}$ each of $\mathrm{dNTP} / \mathrm{l}$ and nucleasefree water. The same cycling conditions were used for all assays: denaturing at $95^{\circ} \mathrm{C}$ for $15 \mathrm{~min} ; 35$ cycles at $95^{\circ} \mathrm{C}$ for $10 \mathrm{~s}$, at $59,3^{\circ} \mathrm{C}$ for $30 \mathrm{~s}$, and at $72^{\circ} \mathrm{C}$ for $30 \mathrm{~s}$; an additional elongation step was performed at $72^{\circ} \mathrm{C}$ for

Table 1 qRT-PCR targets with corresponding Affymetrix probeset ID and primer used for amplification

\begin{tabular}{llll}
\hline Target & Affymetrix cluster ID & Forward primer & Reverse primer \\
\hline HOXA5 & 8138735 & CGCCCAACCCAGATCTA & GGCCGCCTATGTTGCATG \\
HOXA9 & 8138749 & GCTTGTGGTCTCCTCCAGT & CCAGGGTCTGTGTITGTA \\
PGR & 7951165 & TGGTGTTGGTCTAGGATGGA & GGATCTGCCACATGGTAAGG \\
ESR1 & GCAGGGAGAGGAGTTGTGT & CAGGACTCGGTGATATGG \\
OXTR & GCACGGTCAAGATGACTTC & GCATGTAGATCCAGGGGTG \\
PEG10 & 8085138 & GACCCCATCCTTCCTGTCTT & GCTTCACTTCTGTGGGGATG \\
MFAP5 & 8134339 & TGCTCTCGTCTTGTCTGTAAGG & ACAGGGAGAAGTCGGAAGT \\
IRS1 & 7960919 & GTTCCAGAAGCAGCCAGAG & GGAAGATATGAGGTCCTAGTTGGA \\
IRS2 & 8059470 & CTTCTTGTCCCACCACTTGA & CAGTGCTGAGCGTCTTCTTIT \\
IGF2 & 7972745 & ACACCCTCCAGTTCGTCTGT & CGGAAACAGCACTCCTCAA \\
WISP2 & 7937772 & GCGACCAACTCCACGTCT & GTCTCCCCTTCCCGATACA \\
CDH5 & 8062864 & ACAACGAGGGCATCATCAA & AATGACCTGGGCTCTGTTC \\
SDHA & 7996264 & AGAAGCCCTTTGAGGAGCA & CGATTACGGGTCTATATTCCAGA \\
PDHB & 8104166 & GAGGCTGGCCACAGTTTG & GAAATGAACGCAGGACCTT \\
PGRMC1 & 8088384 & GGTGTCGATGTGACCAAAG & TGAGGTCAGAAAGGTCATCGT \\
HISPPD1 & 8169617 & TCCATCATCTGACGTTCCAC & TGGTGTGGGAGGATCTTG \\
\hline
\end{tabular}


Table 2 Pyrosequencing targets with corresponding Illumina probeset ID and primer used for amplification

\begin{tabular}{|c|c|c|c|c|}
\hline Target & Illumina Target ID & Forward primer & Reverse primer & Sequencing primer \\
\hline WISP2 & cg03562120 & GTGTGTGTTTGGGAGTGATTT & Bio-CTCATATCCCCTACAAAACCAACTTTAA & GTTTGGGAGTGATTTATAGTTGT \\
\hline HOXA5 & $\operatorname{cg} 02248486$ & $\begin{array}{l}\text { GGAATTATGATTITTATAATTAT } \\
\text { GTAATTGGTAGTT }\end{array}$ & Bio-AACCACAAATCAAACACACATATCA & $\begin{array}{l}\text { AATTATGATTITTATAATTATGTAA } \\
\text { TTGGTAG }\end{array}$ \\
\hline HOXA9 & cg27009703 & Bio-GTGGTGATGGTGGTGGTATAT & ACTTCAACCCCTACAACTTCCAATCCA & $\begin{array}{l}\text { TCAACCCCTACAACTTCCAATCCA } \\
\text { AAA }\end{array}$ \\
\hline WT1 & $\operatorname{cg} 25094569$ & Bio-TGGATGTGATITTGGGATAGGT & CCCATTTTAAAAACCAAACCATTTAACT & $\begin{array}{l}\text { ATITITAAAAAATAAACAACCTTC } \\
\text { TCTATC }\end{array}$ \\
\hline GATA4 & cg17795240 & AAGGATTGGTTAGGGAGAGTTTGTTTG & $\begin{array}{l}\text { Bio-TAAAATTTCACCATATTAACCAAAAACT } \\
\text { CCTAACCTTA }\end{array}$ & GGTTAGGGAGAGTTTGTITG \\
\hline
\end{tabular}

3 min. Gel electrophoresis was carried out on all PCR products. All PCR reactions included a no-template control and four standardized methylation controls $(0 \%$, $30 \%, 70 \%$, and $100 \%$ methylated DNA). Pyrosequencing was carried out using the Pyrosequencer PSQ $96 \mathrm{MA}$ (Biotage AB, Uppsala, Sweden). Results were automatically analyzed using the PSQ 96MA 1.0 software (Allele Quantification mode).

\section{Pathway analysis}

Gene regulation networks were generated using Ingenuity Pathway analysis software (ingenuity ${ }^{\circledR}$ systems, http://www.ingenuity.com). The dataset with differentially regulated transcripts and their corresponding expression and methylation values were uploaded into the application. The genes were overlaid onto a global molecular network developed from information in the Ingenuity Pathways Knowledge Base. Networks of these focus genes were then algorithmically generated based on their connectivity. All edges are supported by at least one reference from the literature, from a textbook, or from canonical information stored in the Ingenuity Pathways Knowledge Base. Genes from the microarray dataset that met the fold change cutoff of 1.5 and that were associated with a relevant pathway in the Ingenuity Pathways Knowledge Base were included in the analysis.

\section{Statistical methods}

With quantitative RT-PCR normalized values were obtained from qBase. The ratio of means of patients divided by means of controls was then calculated and the $\log 2$ of this ratio is shown. For the Affymetrix microarray analysis the means of patients were divided by the means of controls and the $\log 2$ was shown as log fold change. Measurement errors were calculated using Gaussian error propagation. As usual it is assumed that normalized values obtained from qBase are lognormal distributed and a t-test (i.e. the Welch test assuming unequal variances) was applied for each gene to investigate the difference between patients and controls in qRT-PCR. The same was done for expression array data. A significance level of 5\% was chosen. The percentage of methylated cytosines was obtained from pyrosequencing methylation analysis. The difference means of patients minus means of controls are shown. The same was done for the average beta values.

\section{Results}

\section{Microarray expression and methylation analysis}

To identify changes in the expression level of putative candidate genes, we performed microarray analysis with Affymetrix Human Gene 1.0. Analysis using the ArrayAssist 4.0 software identified 293 transcripts differentially expressed between tissue samples of MRKH patients and controls. Of these transcripts, 161 were upregulated and 132 downregulated with a fold change of at least 1.5 and a p-value of less than 0.05 (Table 3).

Pathway analysis revealed genes relevant in the embryological development of the genital tract, including HOXA genes and hormone receptors.

The delineation of regional DNA methylation patterns has important implications for understanding why certain regions of the genome can be expressed in specific developmental contexts and how epigenetic changes might enable aberrant expression patterns and disease [27]. We therefore decided to compare whole-genome expression and methylation patterns in uterine rudiments of MRKH patients compared to control uteri. To achieve this, we performed Illumina HumanMethylation27 BeadArrays and overlaid both datasets. The analysis using the BeadStudio software identified 194

Table 3 Differential expression of genes and methylation of CpG-sites in MRKH patients compared to controls in numbers

\begin{tabular}{ll}
\hline Difference in patients from controls & $\mathbf{n}$ \\
\hline Differential expression, total & 293 \\
Downregulated & 132 \\
Upregulated & 161 \\
\hline Differential methylation, total & 194 \\
Hypomethylated & 116 \\
Hypermethylated & 78 \\
\hline Overlap & 9 \\
\hline
\end{tabular}


differentially methylated $\mathrm{CpG}$ sites in specific $\mathrm{CpG}$ islands. Of these sites, 78 were hypermethylated and 116 hypomethylated (Table 3).

Nine genes were detected in both datasets (HOXA5, HOXA9, WISP2, CDH5, PEG10, MFAP5, LRRC32, RALGPS2, SMPD3); these are termed 'overlap genes' (Table 4). CpG sites within these genes were either hypermethylated and the genes underexpressed or hypomethylated and overexpressed, except for one gene.

Of the nine overlap genes, six (CDH5, MFAP5, WISP2, HOXA5, PEG10, HOXA9) were included in the subsequent analyses and experiments as they are known to be relevant to the embryological development of the female genital tract.

\section{Network and pathway analysis}

Ingenuity Pathways analysis software (Ingenuity Systems) was used to examine the connection between the differentially methylated $\mathrm{CpG}$ sites and differentially expressed genes. As shown in Figures 1 and 2, differentially expressed genes and differentially methylated sites can be assigned to basic functions relevant to cell and tissue development and proliferation, cell-to-cell signaling and interaction, cellular movement, cancer, endocrine and reproductive disorders, and others (Figure 1 and 2).

Figure 3 shows a network of differentially regulated overlap genes and other relevant genes. The network was created by fusing the expression and methylation datasets from the microarray experiments. This specific network was selected because of the known relevance of the genes included during embryological development and during functional changes of the female reproductive tract. Interactions between embryologically relevant genes, including HOXA genes and hormone receptors, can be clearly detected. Interacting genes are either differentially expressed, carry differentially methylated CpG sites, or both. The gene regulation network contains 15 differentially regulated genes, seven downregulated (green icons), two of these also with hypermethylated CpG sites (dark grey), and seven upregulated (red icons), three of these also with hypomethylated CpG sites (light grey). Four genes contained differentially methylated CpG sites without being differentially expressed (three hypo- and one hypermethylated). Eight genes are supplemented in the network to complete the interactions. Eleven of the transcripts shown were used for qRT-PCR validation and five for pyrosequencing.

Figure 4 shows the relation between expression and methylation in overlap genes later selected for validation. CpG sites in genes were either hypomethylated with genes overexpressed or hypermethylated with genes underexpressed, except for CDH5.

\section{Validation of expression differences by qRT-PCR}

We chose nine key players in the interaction networks for independent verification by qRT-PCR. The genes were selected because of their known relevance during embryological development. Three suitable reference genes (PDH, SDHA, PGRMC1 or HISPPD1) were selected according to their $\mathrm{M}$-values and used for normalization of the qRT-PCR reactions. We were able to validate all nine genes. The results of the qRT-PCR (Figure 5) showed $100 \%$ validation efficiency in comparison to the expression data of the microarray experiment, although statistical significance was not always found.

\section{Validation of methylation differences by pyrosequencing} Five embryologically important genes were chosen for validation of the methylation array experiments by

Table 4 Overlap genes: names of differentially expressed genes that contain differentially methylated CpG-sites

\begin{tabular}{|c|c|c|c|c|c|c|c|}
\hline $\begin{array}{l}\text { Probe set ID, } \\
\text { human } 1.0 \\
\text { genechip array }\end{array}$ & $\begin{array}{l}\text { Probe set ID, } \\
\text { 27human } \\
\text { methylation }\end{array}$ & Gene title & $\begin{array}{l}\text { Gene } \\
\text { symbol }\end{array}$ & $\begin{array}{l}\text { Fold change } \\
\text { human } 1.0 \\
\text { genechip array }\end{array}$ & $\begin{array}{l}\mathrm{p}- \\
\text { value }\end{array}$ & $\begin{array}{l}\text { Diff methyl } \\
\text { 27human } \\
\text { methylation array }\end{array}$ & $\begin{array}{l}\mathrm{p}- \\
\text { value }\end{array}$ \\
\hline 8138735 & cg02248486 & homeobox A5 & HOXA5 & 1.9 & 0.00036 & -0.33 & 0.00015 \\
\hline 8138749 & cg26521404 & homeobox A9 & HOXA9 & 1.5 & na & -0.23 & 0.00047 \\
\hline 8062864 & cg03562120 & $\begin{array}{l}\text { WNT1-inducible signaling pathway } \\
\text { protein } 2\end{array}$ & WISP2 & -1.7 & 0.00148 & 0.14 & 0.00096 \\
\hline 7996264 & cg22319147 & $\begin{array}{l}\text { cadherin 5, type 2, VE-cadherin } \\
\text { (vascular epithelium) }\end{array}$ & $\mathrm{CDH} 5$ & -1.6 & 0.00503 & -0.12 & 0.00598 \\
\hline 8134339 & cg19107595 & paternally expressed 10 & PEG10 & 1.8 & 0.00290 & -0.12 & 0.01596 \\
\hline 7960919 & cg15815843 & Microfibrillar-associated protein 5 & MFAP5 & -2.1 & 0.04635 & 0.16 & 0.02451 \\
\hline 7950555 & cg20899321 & Leucine-rich repeat containing 32 & LRRC32 & -1.6 & 0.00435 & 0.12 & 0.00045 \\
\hline 7907657 & cg10559803 & $\begin{array}{l}\text { Ral GEF with PH domain and } \mathrm{SH} 3 \\
\text { binding motif } 2\end{array}$ & RALGPS2 & 2.0 & 0.00385 & -0.11 & 0.00345 \\
\hline 8002249 & cg17217677 & $\begin{array}{l}\text { sphingomyelin phosphodiesterase 3, } \\
\text { neutral membrane (neutral } \\
\text { sphingomyelinase II) }\end{array}$ & SMPD3 & 1.6 & 0.00001 & -0.10 & 0.01602 \\
\hline
\end{tabular}




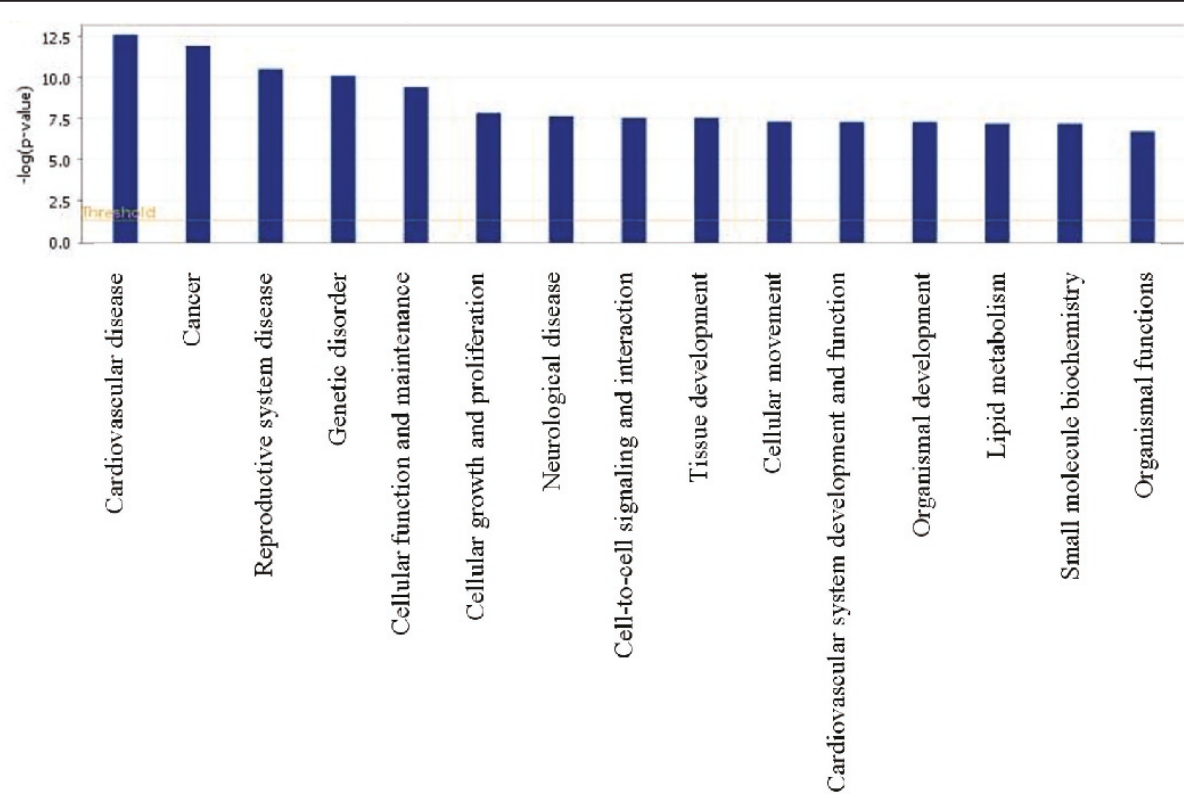

Figure 1 Assignment of differentially expressed genes to functional groups. Assignment of all differentially expressed genes to functional groups. The analysis was done with Ingenuity Pathways analysis software. Fischer's exact test was used to test for significance (shown as bars), determining the probability that each biological function assigned to the network is due to chance alone.

pyrosequencing. We selected one to five $\mathrm{CpG}$ sites within one specific $\mathrm{CpG}$ island per gene for analysis (Figure 6). The $\mathrm{CpG}$ islands were selected according to the differential methylation in the preceding array experiments. The differential methylation status of the array experiments was confirmed for all five $\mathrm{CpG}$ islands within the WISP2, HOXA5, HOXA9, GATA4 and WT1 genes, thus validation efficiency was again 100\% (Figure 7).

\section{Discussion}

Although MRKH syndrome is a congenital disorder most patients are not diagnosed until puberty. Using a candidate gene approach, the underlying cause has so

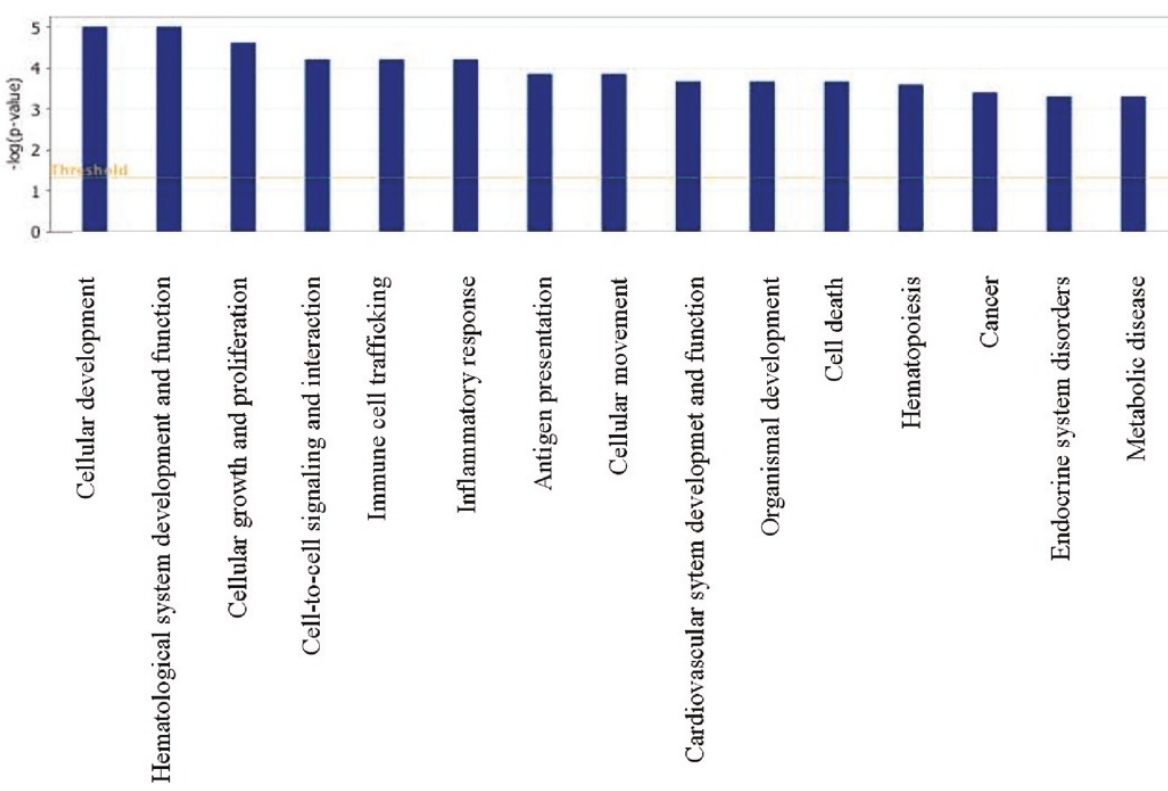

Figure 2 Assignment of all genes containing differentially methylated CpG-sites to functional groups. Fischer's exact test was used to test for significance (shown as bars), determining the probability that each biological function assigned to the network is due to chance alone. 


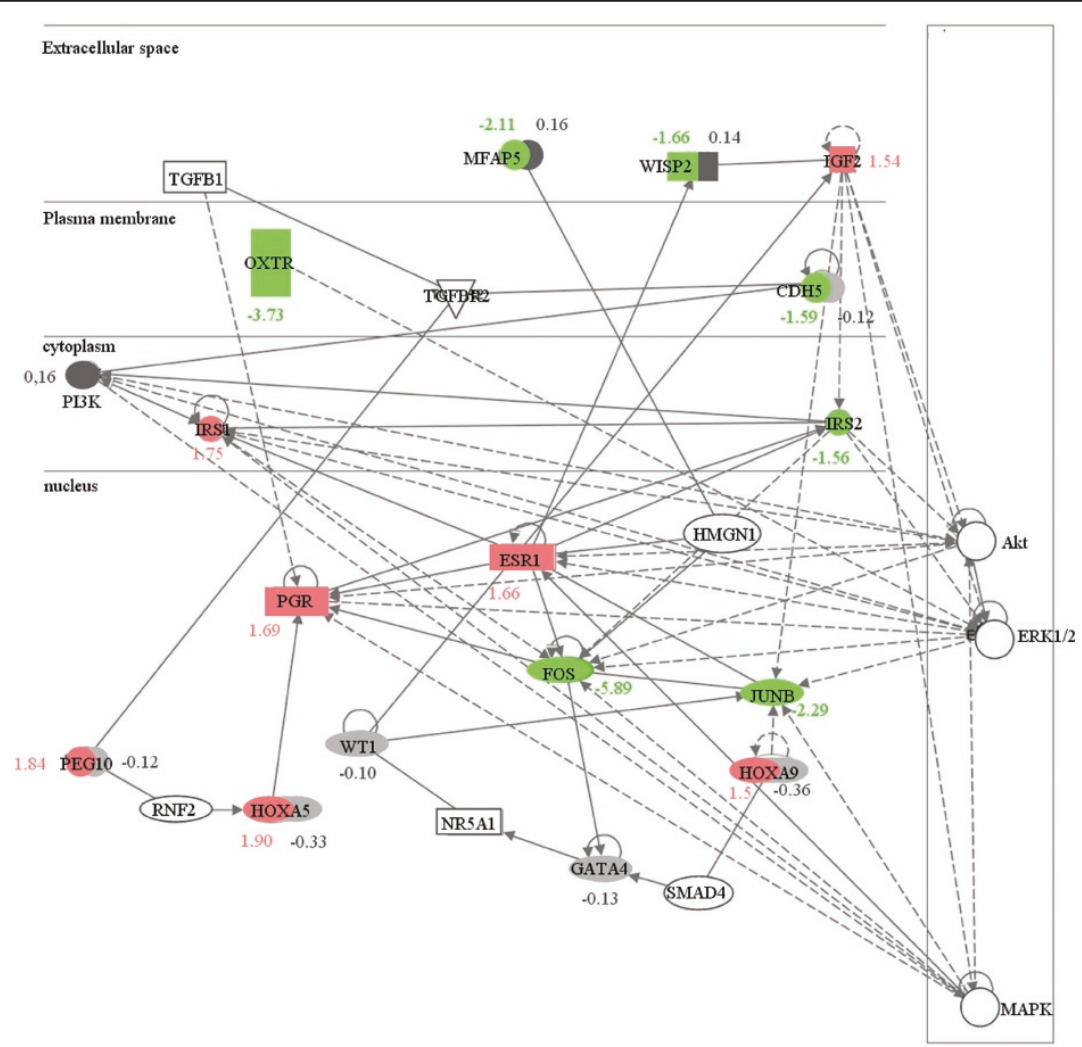

Figure 3 Network of differentially expressed genes and genes containing differentially methylated CpG-sites. The fold change of regulation in the microarray analysis, (the p-value of the significance analysis) and the percentage of differential methylation are listed below the symbols. For the purposes of simplification, only selected known gene-to-gene interactions are shown. Continuous arrow lines show direct interactions between genes and broken arrow lines show indirect interactions.

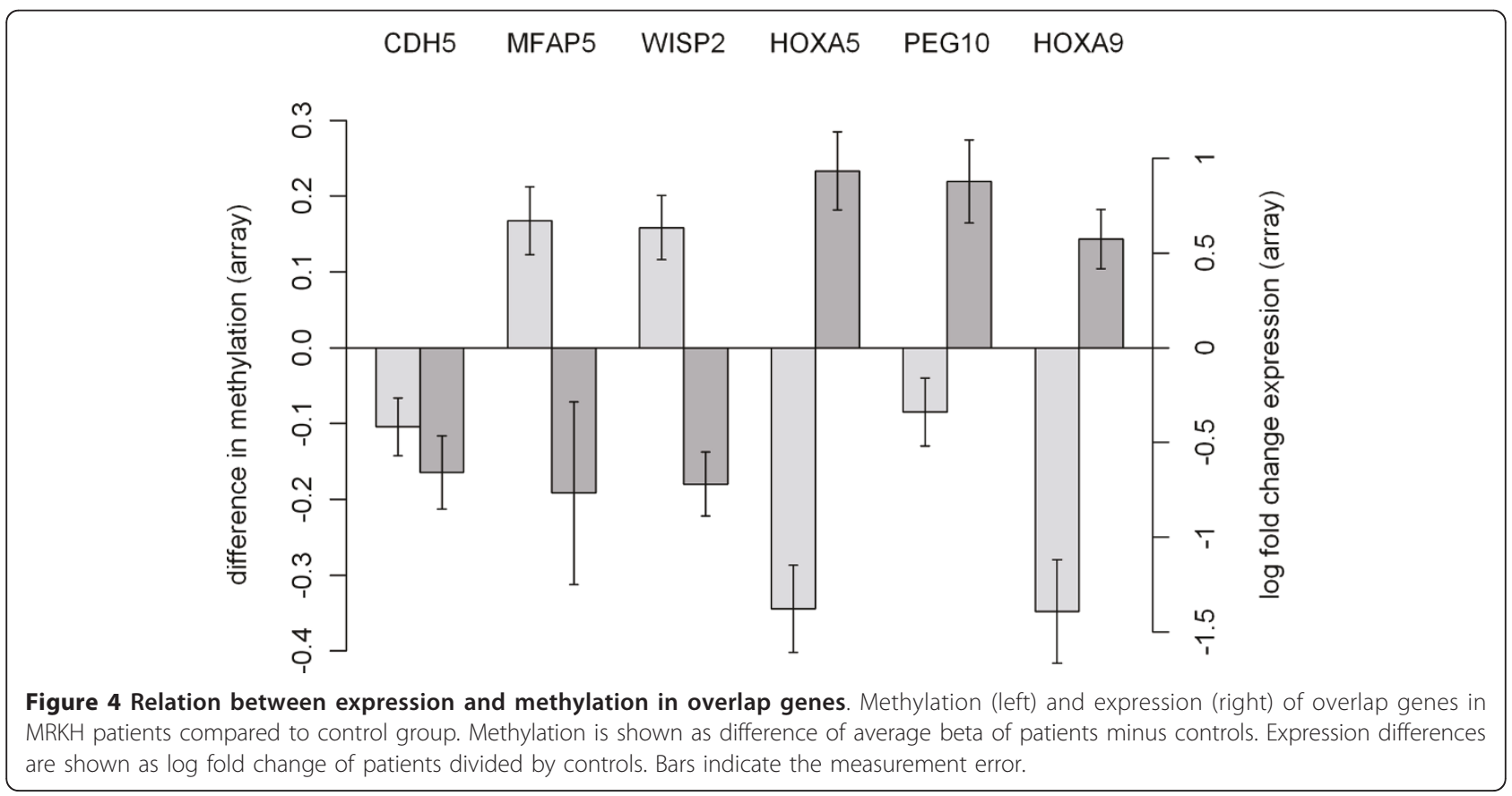




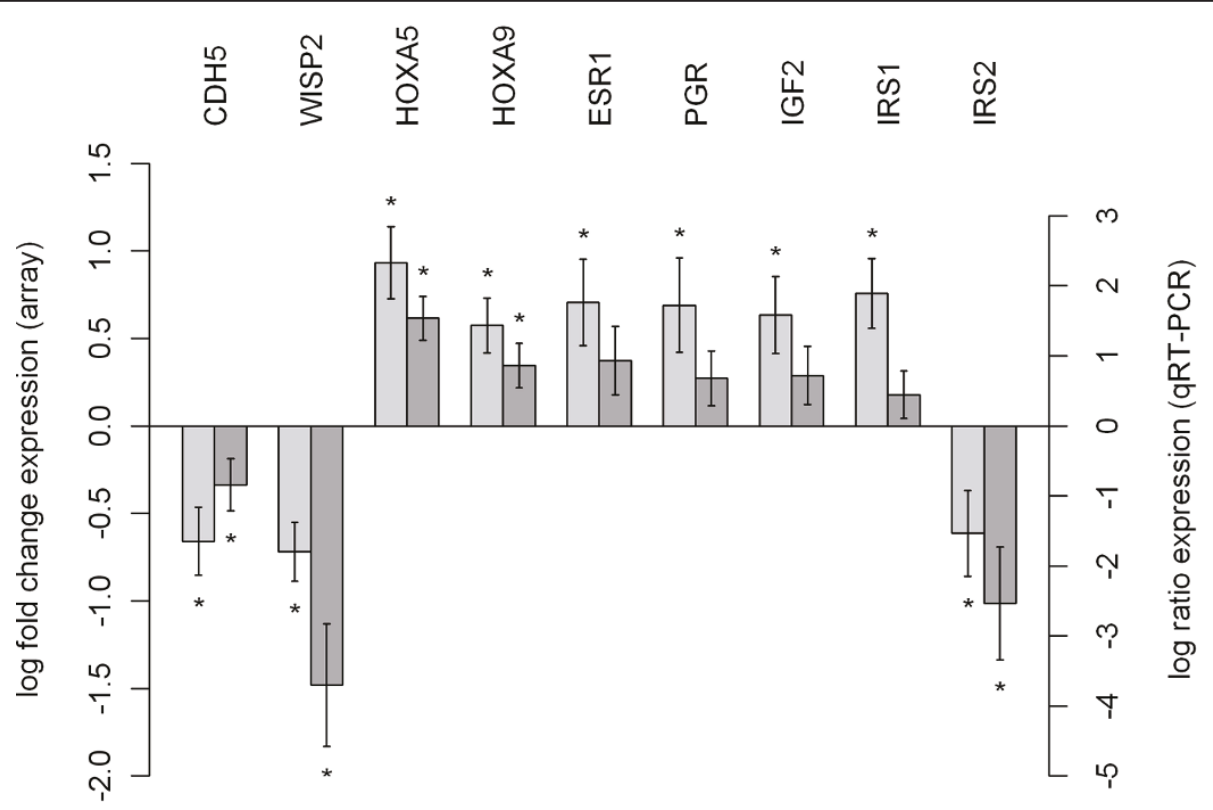

Figure 5 Validation of differential expression by qRT-PCR. Expression of overlap genes in MRKH patients compared to control group measured by array (left) and qRT-PCR (right). Array data are shown as log fold change of patients divided by controls, qRT-PCR data are shown as log ratio of patients divided by controls. Bars indicate the measurement error and stars indicate a significant difference between patients and controls (t-test, p-values <0.05).

far not been identified [5]. Recently, a high incidence of recurrent copy number variants in patients with isolated and syndromic Müllerian aplasia has been described, but none of them was consistently found in a larger group of patients [25]. Cases of discordant monozygotic twins suggest that the involvement of epigenetic factors is more likely. The present study was the first to use a whole-genome approach to identify relevant genes, including differential expression and methylation. This allowed us to create a complex network of genes, which

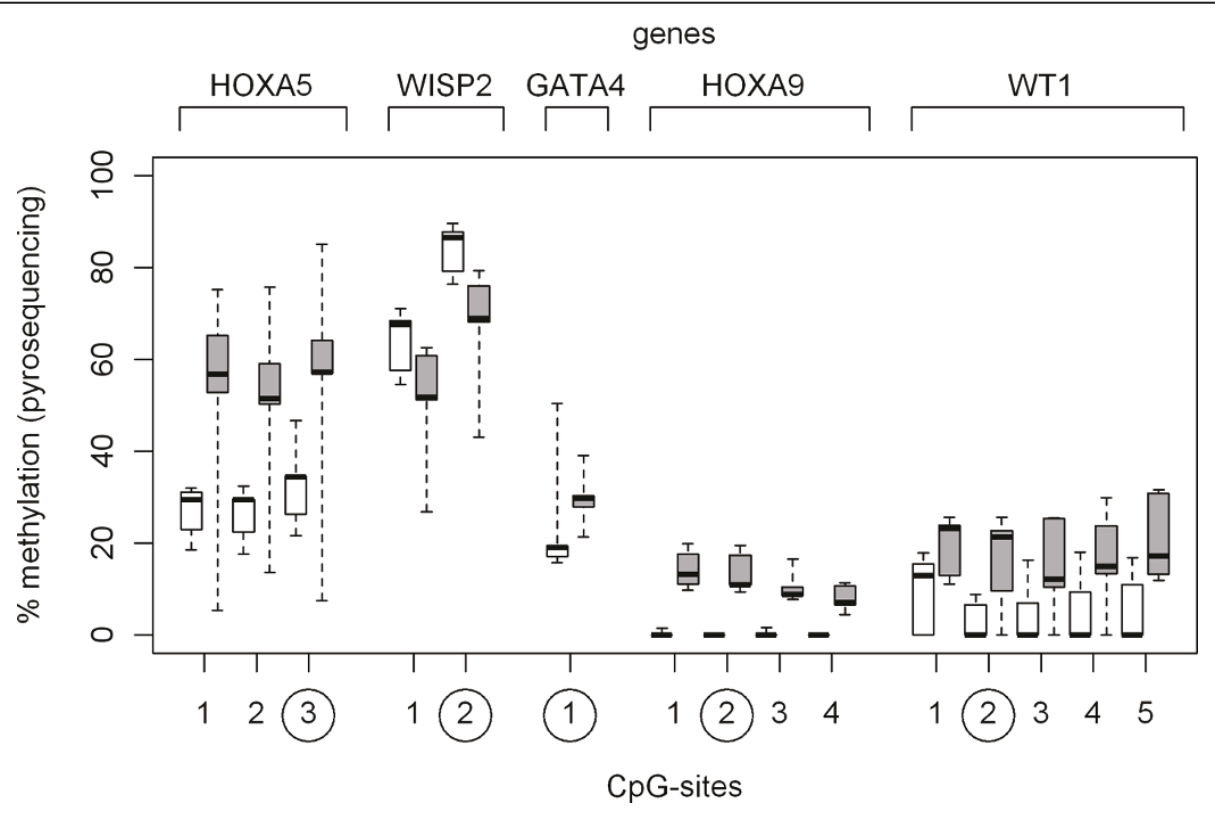

Figure 6 Similar methylation in adjacent CpG sites within CpG islands. Degree of methylation within CpG islands: shown are box-andwhisker plots of the percentage of methylated cytosines for patients (white boxes) and contols (grey boxes). The circled CpG sites correspond to the specific sites detected in the array experiments. 


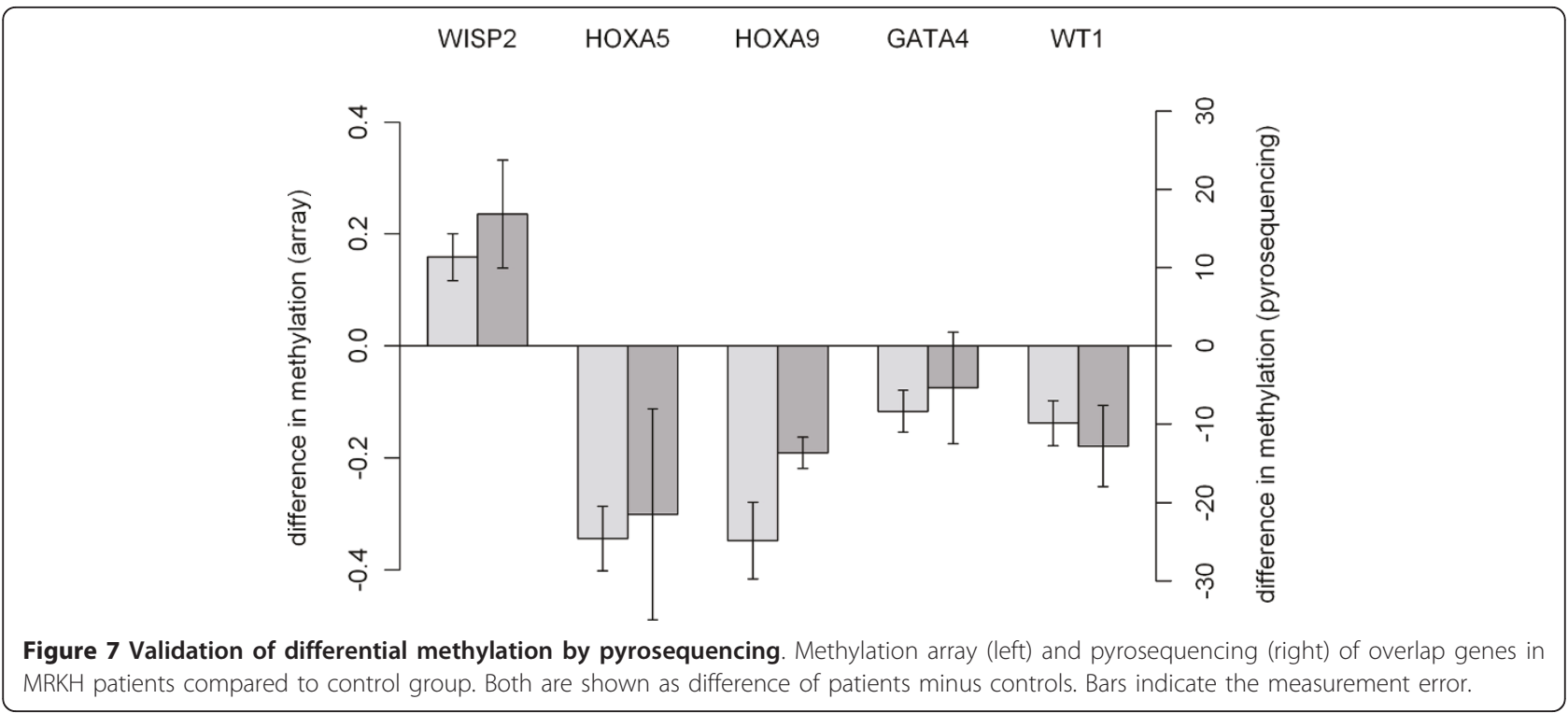

provided insight into possible mechanisms underlying MRKH syndrome. Our data indicate that different potential mechanisms are possible.

\section{Deficiency of hormone receptors}

The overexpression of ESR1 and PGR in rudimentary uterine tissue from MRKH patients could be explained by a deficiency of these hormone receptors. The local overexpression may be the result of a positive feedback mechanism well known from other hormonal regulatory loops. Similar hypotheses have been postulated before but firm scientific evidence has not yet been obtained. This is the first study with an experimental setting that supports the hypothesis of locally deficient hormone receptors in MRKH syndrome.

As early as 1910, Küster explained the MRKH syndrome by regression of the Müllerian duct (MD) [34]. According to Ludwig, the MRKH syndrome results from non-fusion of the MD with the Wolffian duct (WD) $[35,36]$. Because the embryo is under the influence of maternal hormones, he suggested that both the nonfusion of the MD with the WD and rudimentary development of the vagina are caused by a deficiency of gestagen or estrogen receptors [35,36]. Estrogens are necessary for the embryonic development of the female reproductive tract. The special role of ESR1 in female reproductive tract development has been demonstrated by disrupting the corresponding gene in the mouse, resulting in hypoplastic uterine and vaginal tissue [37].

\section{Influence of estrogen on $\mathrm{AMH}$ and its receptor}

One of the first hypotheses for the underlying cause of MRKH syndrome was an activating mutation of either the gene for the $A M H$ receptor (AMHR), resulting in the inappropriate production of $\mathrm{AMH}$, or the receptor itself. Schmid-Tannwald and Hauser proposed the regression of the MD due to a temporary secretion of $\mathrm{AMH}$ during the first fetal weeks [38]. Depending upon the amount secreted, a greater or lesser portion of the MD regressed. Nevertheless, mutation analyses of the $A M H$ gene did not support a link between the MRKH syndrome and AMH at the genome level. Also, AMH protein levels in plasma and peritoneal fluid from MRKH patients were equivalent to control individuals $[18,23]$. Our study confirmed the data given, as we did not see any persistent differential expression or methylation patterns in the AMH or AMHR genes in adolescent MRKH patients. However, low or baseline AMH levels in a female adolescent may not necessarily be correlated with the patient's early embryonic exposure to $\mathrm{AMH}$ signaling [23].

It has been reported that estrogen regulates $A M H$ expression [39]. The constant overexpression of ESR1 found in the rudimentary uterine tissue in our patients or the in utero exposure to abnormally high maternal levels of $E_{2}$ could lead to an increasing AMH promoter activity during embryological development of the female genital tract causing uterine and vaginal aplasia.

Transcription factors involved in primary sex determination are also recruited as important regulators of AMH transcription. A common regulatory factor important for transcription of $A M H$ genes is WT-1. WT- 1 is essential for the embryonic development of the kidneys and gonads. GATA4 appears to play a predominant role in sex determination and sex differentiation via $A M H$ gene regulation [40]. In our study $\mathrm{CpG}$ sites within WT1 and GATA4 were both hypomethylated compared to the control tissue. This could be a sign of stable 
activation leading, at least during embryological development, to activation of the $A M H$ gene and thus partial regression of the $\mathrm{MD}$.

\section{Influence of endocrine disruptors on the Müllerian duct and on the expression of HOX genes}

Chemical compounds homologous to steroids can act as agonists or antagonists in fetuses exposed to them [37]. The involvement of ED with estrogen-like functions would be an explanation for the findings in MRKH syndrome, although the analyses of pregnancy histories available in all our cases so far failed to identify any clear association with drug use, illness or exposure to known substances.

Several examples of a negative impact of estrogens on uterine development are known. Transient exposure of the neonatal ewe to estrogens during critical periods specifically perturbs normal development of the uterus [41]. Estrogen inhibited caudal progression of developing $\mathrm{MD}$ in the turtle. It has been shown to block development of the MD when applied before the start of differentiation, and the length of the MD varied with the time point treatment was given [42].

Epithelial-mesenchymal differentiation in the murine MD is regulated by WNT signaling correlated with expression of $H O X$ genes. Several nuclear hormonal receptors regulate the expression of multiple $H O X$ genes. When a HOX gene is mutated, the body segment where it is normally expressed typically develops characteristics of the segment anterior to it, an effect known as anterior transformation. In contrast to Drosophila, in vertebrates, targeted mutation in a single $H O X$ gene usually causes only a subtle transformation. This is because of genetic duplication and functional redundancy of adjacent genes [11]. The hypomethylation of specific $\mathrm{CpG}$ sites and corresponding overexpression of HOXA9 could be due to either exposure to a substance similar to diethylstilbestrol (DES) in utero or a deficient HOXA10 causing anterior transformation.

It is known that HOXA9 is expressed at high levels in areas destined to become the fallopian tube, HOXA10 is expressed in the developing uterus, HOXA11 is expressed in the primordia of the lower uterine segment and cervix, and that HOXA13 is expressed in the ectocervix and upper vagina. This expression pattern has been preserved in mice and humans [43]. Microarray analysis has shown organ-specific changes in gene expression profiles in the oviduct, uterus, and vagina after DES exposure. Changes in HOX and WNT expression might lead to abnormalities of segment-related positional identity in the upper part of the MD after DES exposure $[43,44]$. Sex steroids have been investigated in the regulation of the HOX genes at the 5 'end of the cluster that determine posterior development, including development of the reproductive tract [45-48]. Both, HOXA10 and HOXA11 expression, is upregulated by $17 ß$-estradiol and progesterone. Changes in $H O X$ gene expression are a potential marker for the effects of in utero drug use that may become apparent only at late stages of development [12]. In utero, DES exposure shifts $H O X A 9$ expression from the oviducts to the uterus and decreases HOXA10 as well as HOXA11 expression of the uterus causing a 'T-shaped' uterus with a tube-like phenotype [47]. In human uterine and cervical cell cultures, DES has induced HOXA9 or HOXA10 gene expression [12].

Continued $H O X$ gene expression in the adult has been described in the reproductive tract and may be a mechanism to retain developmental plasticity [49]. Specifically HOXA10 and 11 are expressed in the endometrium and their expression varies in a menstrual cycledependent manner. Although no women with mutations in $H O X A 10$ and HOXA11 have been described, patients with lower implantation rates have lower HOXA10 and HOXA11 expression in the secretory phase [43].

In addition to HOXA9, specific CpG sites in HOXA5 were hypomethylated and the gene overexpressed. This gene has a crucial role in the specification of the cervical and upper thoracic region of the skeleton. Its correct expression is important for the proper patterning of the embryo. It has been shown that ectopic HOXA5 expression results in abnormal differentiation [50]. In a similar manner, ectopic HOXA5 expression at the 5'end of the cluster might prevent normal differentiation of the MD or even regression. HOXA5 is known as a transcriptional regulator of multiple target genes, two of which are $p 53$ and the progesterone receptor (PGR). The overexpression of $P G R$ in patients may be induced directly by the overexpression of HOXA5 [51].

Finally, neonatal DES exposure is also known to cause overexpression of IRS-1 and IGF2, both of which are included in our network [52].

\section{Impact of WNT genes on uterine development}

The WNT genes and products form the WNT signaling pathway which controls developmental processes. Only the WNT4 gene has been clearly implicated in atypical MRKH syndrome before [9]. The phenotype of WNT9b mutants can be rescued by activation of WNT1 in the WD, identifying the canonical WNT pathway as a determinant signaling process in MD elongation [37]. A recent study excluded mutations in the coding sequences of WNT4, WNT5A, WNT7A and WNT9B in $11 \mathrm{MRKH}$ patients [6]. In our study, CpG sites within the WISP2 (WNT1 inducible signaling pathway protein 2) gene were hypermethylated and the gene underexpressed in rudimentary uterine tissue, thus the relevance is not clear yet. WISP2 (CCN5), a gene that is important 
in smooth muscle cell proliferation and migration, is an estrogen-induced gene in the uterus [53].

\section{Conclusion}

We were able to draw important conclusions from our study, the first to compare rudimentary uterine tissue from MRKH patients and uterine tissue from healthy controls. GATA4, WT1 and constant overexpression of ESR1 might increase AMH promoter activity during embryological development, resulting in partial regression of the MD. Involvement of endocrine disruptors (ED) with estrogen-like functions might mimic this effect. The deficiency of hormone receptors may result in their overexpression and cause both the non-fusion of the MD with the WD and rudimentary development of the vagina.

The hypomethylation of specific CpG sites and the corresponding overexpression of HOXA9 may be due to either exposure to a substance similar to DES in utero or deficient HOXA10 causing anterior transformation. Ectopic HOXA5 expression at the 5'end of the cluster might prevent normal differentiation of the MD.

Using the synergetic approach of transcriptional and epigenetic regulation, our study has, for the first time, provided a deeper insight into the etiology of congenital vaginal and uterine aplasia, and has significantly advanced the explanation of MRKH syndrome. Further investigations will show which of our hypotheses is correct, but it is already clear that hormone receptors and $H O X$ genes appear to play a major role and should be in focus of further examinations.

\section{Ethics Approval}

This study was conducted with the approval of the Ethics Review Board of Eberhard-Karls-University, Tuebingen, Germany.

\section{Acknowledgements}

The authors thank all patients who participated in this study. KR was the recipient of a temporary research fellowship within the PATE/ fortüne program of the Eberhard-Karls-University of Tuebingen, number: 1835-0-0.

\section{Author details}

'University Hospital Tuebingen, Department of Obstetrics and Gynecology, Tuebingen, Germany. ${ }^{2}$ University Hospital Tuebingen, Department of Medical Genetics, Microarray Facility, Tuebingen, Germany.

\footnotetext{
Authors' contributions

KR and SB carried out the sample collection. KR drafted the manuscript. KR and $G B$ performed the $P C R$ and pyrosequencing experiments. $M B$ and $M W$ and SP carried out the microarrays and their analyses. MW, SP, KH and KS helped with the experiments. BS performed the statistical analysis. SB and $\mathrm{MB}$ participated in the study design and coordination and $\mathrm{MB}, \mathrm{OR}$ and $\mathrm{DW}$ helped to draft the manuscript. All authors read and approved the final manuscript.
}

\section{Competing interests}

The authors declare that they have no competing interests.
Received: 7 March 2011 Accepted: 28 May 2011 Published: 28 May 2011

\section{References}

1. Folch M, Pigem I, Konje JC: Müllerian agenesis: etiology, diagnosis, and management. Obstet Gynecol Surv 2000, 55(10):644-9.

2. Ledig S, Schippert C, Strick R, Beckmann MW, Oppelt PG, Wieacker P: Recurrent aberrations identified by array-CGH in patients with MayerRokitansky-Küster-Hauser syndrome. Fertil Steril 2011, 95(5):1589-94.

3. Wottgen M, Brucker S, Renner SP, Strissel PL, Strick R, Kellermann A, Wallwiener D, Beckmann MW, Oppelt P: Higher incidence of linked malformations in siblings of Mayer-Rokitansky-Küster-Hauser-syndrome patients. Hum Reprod 2008, 23(5):1226-31.

4. Morcel K, Camborieux L, Programme de Recherches sur les Aplasies Mülériennes, Guerrier D: Mayer-Rokitansky-Küster-Hauser (MRKH) syndrome. Orphanet J Rare Dis 2007, 2:13.

5. Sultan C, Biason-Lauber A, Philibert P: Mayer-Rokitansky-Kuster-Hauser syndrome: recent clinical and genetic findings. Gynecol Endocrinol 2009, 25(1):8-11.

6. Ravel C, Lorenço D, Dessolle L, Mandelbaum J, McElreavey K, Darai E, Siffroi JP: Mutational analysis of the WNT gene family in women with Mayer-Rokitansky-Kuster-Hauser syndrome. Fertil Steril 2009, 91 (4 Suppl):1604-7.

7. Cheroki C, Krepischi-Santos AC, Rosenberg C, Jehee FS, Mingroni-Netto RC, Pavanello Filho I, Zanforlin Filho S, Kim CA, Bagnoli VR, Mendonça BB, Szuhai K, Otto PA: Report of a del22q11 in a patient with MayerRokitansky-Küster-Hauser (MRKH) anomaly and exclusion of WNT-4, RARgamma, and RXR-alpha as major genes determining MRKH anomaly in a study of 25 affected women. Am J Med Genet A 2006, 140(12):1339-42.

8. Cheroki C, Krepischi-Santos AC, Szuhai K, Brenner V, Kim CA, Otto PA, Rosenberg C: Genomic imbalances associated with mullerian aplasia. J Med Genet 2008, 45(4):228-32.

9. Biason-Lauber A, Konrad D: WNT4 and sex development. Sex Dev 2008, 2(4-5):210-8.

10. Philibert P, Biason-Lauber A, Rouzier R, Pienkowski C, Paris F, Konrad D, Schoenle E, Sultan C: Identification and functional analysis of a new WNT4 gene mutation among 28 adolescent girls with primary amenorrhea and müllerian duct abnormalities: a French collaborative study. J Clin Endocrinol Metab 2008, 93(3):895-900.

11. Daftary GS, Taylor HS: Endocrine regulation of HOX genes. Endocr Rev 2006, 27(4):331-55.

12. Block K, Kardana A, Igarashi P, Taylor HS: In utero diethylstilbestrol (DES) exposure alters Hox gene expression in the developing müllerian system. FASEB J 2000, 14(9):1101-8.

13. Guerrier D, Mouchel T, Pasquier L, Pellerin I: The Mayer-Rokitansky-KüsterHauser syndrome (congenital absence of uterus and vagina)-phenotypic manifestations and genetic approaches. J Negat Results Biomed 2006, 5:1.

14. Mortlock DP, Innis JW: Mutation of HOXA13 in hand-foot-genital syndrome. Nat Genet 1997, 15(2):179-80.

15. Goodman FR, Bacchelli C, Brady AF, Brueton LA, Fryns JP, Mortlock DP, Innis JW, Holmes LB, Donnenfeld AE, Feingold M, Beemer FA, Hennekam RC, Scambler PJ: Novel HOXA13 mutations and the phenotypic spectrum of hand-foot-genital syndrome. Am J Hum Genet 2000, 67(1):197-202.

16. Burel A, Mouchel T, Odent S, Tiker F, Knebelmann B, Pellerin I, Guerrier D: Role of HOXA7 to HOXA13 and PBX1 genes in various forms of MRKH syndrome (congenital absence of uterus and vagina). J Negat Results Biomed 2006, 5:4.

17. Lalwani $\mathrm{S}, \mathrm{Wu} \mathrm{HH}$, Reindollar RH, Gray MR: HOXA10 mutations in congenital absence of uterus and vagina. Fertil Steril 2008, 89(2):325-30.

18. Oppelt P, Strissel PL, Kellermann A, Seeber S, Humeny A, Beckmann MW, Strick R: DNA sequence variations of the entire anti-Mullerian hormone (AMH) gene promoter and $\mathrm{AMH}$ protein expression in patients with the Mayer-Rokitansky-Kuster-Hauser syndrome. Hum Reprod 2005, 20(1):149-57.

19. Visser JA: AMH signaling: from receptor to target gene. Mol Cell Endocrinol 2003, 211(1-2):65-73.

20. Guioli S, Sekido R, Lovell-Badge R: The origin of the Mullerian duct in chick and mouse. Dev Biol 2007, 302(2):389-98.

21. Orvis GD, Behringer RR: Cellular mechanisms of Müllerian duct formation in the mouse. Dev Biol 2007, 306(2):493-504. 
22. Josso N, Belville C, di Clemente N, Picard JY: $\mathrm{AMH}$ and $\mathrm{AMH}$ receptor defects in persistent Müllerian duct syndrome. Hum Reprod Update 2005, 11(4):351-6.

23. Resendes BL, Sohn SH, Stelling JR, Tineo R, Davis AJ, Gray MR, Reindollar RH: Role for anti-Müllerian hormone in congenital absence of the uterus and vagina. Am J Med Genet 2001, 98(2):129-36.

24. Bernardini L, Gimelli S, Gervasini C, Carella M, Baban A, Frontino G, Barbano G, Divizia MT, Fedele L, Novelli A, Béna F, Lalatta F, Miozzo M, Dallapiccola B: Recurrent microdeletion at $17 q 12$ as a cause of MayerRokitansky-Kuster-Hauser (MRKH) syndrome: two case reports. Orphanet J Rare Dis 2009, 4:25.

25. Nik-Zainal S, Strick R, Storer M, Huang N, Rad R, Willatt L, Fitzgerald T, Martin V, Sandford R, Carter NP, Janecke AR, Renner SP, Oppelt PG, Oppelt P, Schulze C, Brucker S, Hurles M, Beckmann MW, Strissel PL, ShawSmith C: High incidence of recurrent copy number variants in patients with isolated and syndromic Müllerian aplasia. J Med Genet 2011.

26. Kaminsky ZA, Tang T, Wang SC, Ptak C, Oh GH, Wong AH, Feldcamp LA, Virtanen C, Halfvarson J, Tysk C, McRae AF, Visscher PM, Montgomery GW, Gottesman II, Martin NG, Petronis A: DNA methylation profiles in monozygotic and dizygotic twins. Nat Genet 2009, 41(2):240-5.

27. Laird PW: Principles and challenges of genome-wide DNA methylation analysis. Nat Rev Genet 2010, 11(3):191-203.

28. Brucker SY, Gegusch M, Zubke W, Rall K, Gauwerky JF, Wallwiener D: Neovagina creation in vaginal agenesis: development of a new laparoscopic Vecchietti-based procedure and optimized instruments in a prospective comparative interventional study in 101 patients. Fertil Steril 2008, 90(5):1940-52.

29. Rasmussen R: Quantification on the LightCycler. In Rapid Cycle Real-time PCR, Methods and Applications. Edited by: Meurer S, Wittwer C and Nakagawara K. Springer Press, Heidel; 2001:21-34

30. Hellemans J, Mortier G, De Paepe A, Speleman F, Vandesompele J: qBase relative quantification framework and software for management and automated analysis of real-time quantitative PCR data. Genome Biol 2007, 8(2):R19.

31. Goossens K, Van Poucke M, Van Soom A, Vandesompele J, Van Zeveren A, Peelman $L$ : Selection of reference genes for quantitative real-time PCR in bovine preimplantation embryos. MC Dev Biol 2005, 5:27.

32. Vandesompele J, De Preter K, Pattyn F, Poppe B, Van Roy N, De Paepe A, Speleman F: Accurate normalization of real-time quantitative RT-PCR data by geometric averaging of multiple internal control genes. Genome Biol 2002, 3(7):RESEARCH0034.

33. Weisenberger D, Van Den Berg D, Pan F, Berman B, Laird P. Comprehensive DNA Methylation Analysis on the Illumina ${ }^{\circledR}$ Infinium ${ }^{\circledast}$ Assay Platform.[http://www.llumina.com/Documents/products/appnotes/ appnote infinium methylation.pdf].

34. Küster H: Uterus bipartitus solidus rudimentarius cum vagina solida. Z Geburtshilfe Gynakol 1910, 67:692-718.

35. Ludwig KS: The Mayer-Rokitansky-Küster syndrome. An analysis of its morphology and embryology. Part I Morphology. Arch Gynecol Obstet 1998, 262(1-2):1-26.

36. Ludwig KS: The Mayer-Rokitansky-Küster syndrome. An analysis of its morphology and embryology. Part II: Embryology. Arch Gynecol Obstet 1998, 262(1-2):27-42

37. Massé J, Watrin T, Laurent A, Deschamps S, Guerrier D, Pellerin I: The developing female genital tract: from genetics to epigenetics. Int I Dev Biol 2009, 53(2-3):411-24

38. Schmid-Tannwald I, Hauser GA: Atypical forms of the Mayer- RokitanskyKuster-syndrome. Geburtshilfe Frauenheilkd 1977, 37:386-392.

39. Chen G, Shinka T, Kinoshita K, Yan HT, Iwamoto T, Nakahori Y: Roles of estrogen receptor alpha (ER alpha) in the regulation of the human Müllerian inhibitory substance (MIS) promoter. J Med Invest 2003, 50(34):192-8.

40. Miyamoto Y, Taniguchi H, Hamel F, Silversides DW, Viger RS: A GATA4/WT1 cooperation regulates transcription of genes required for mammalian sex determination and differentiation. BMC Mol Biol 2008, 9:44.

41. Hayashi K, Carpenter KD, Spencer TE: Neonatal estrogen exposure disrupts uterine development in the postnatal sheep. Endocrinology 2004, 145(7):3247-57.

42. Dodd KL, Wibbels T: Estrogen inhibits caudal progression but stimulates proliferation of developing müllerian ducts in a turtle with temperature- dependent sex determination. Comp Biochem Physiol A Mol Integr Physiol 2008, 150(3):315-9.

43. Taylor HS: Endocrine disruptors affect developmental programming of HOX gene expression. Fertil Steril 2008, 89(2 Suppl):e57-8.

44. Suzuki A, Urushitani H, Sato T, Kobayashi T, Watanabe H, Ohta Y, Iguchi T: Gene expression change in the Müllerian duct of the mouse fetus exposed to diethylstilbestrol in utero. Exp Biol Med (Maywood) 2007, 232(4):503-14

45. Cermik D, Karaca M, Taylor HS: HOXA10 expression is repressed by progesterone in the myometrium: differential tissue-specific regulation of HOX gene expression in the reproductive tract. J Clin Endocrinol Metab 2001, 86(7):3387-92.

46. Ma L, Benson GV, Lim H, Dey SK, Maas RL: Abdominal B (AbdB) Hoxa genes: regulation in adult uterus by estrogen and progesterone and repression in müllerian duct by the synthetic estrogen diethylstilbestrol (DES). Dev Biol 1998, 197(2):141-54.

47. Du H, Taylor HS: Molecular regulation of mullerian development by Hox genes. Ann N Y Acad Sci 2004, 1034:152-65.

48. Taylor HS: The role of HOX genes in the development and function of the female reproductive tract. Semin Reprod Med 2000, 18(1):81-9.

49. Morgan R: Hox genes: a continuation of embryonic patterning? Trends Genet 2006, 22(2):67-9.

50. Aubin J, Lemieux $M$, Tremblay $M$, Behringer RR, Jeannotte L: Transcriptional interferences at the Hoxa4/Hoxa5 locus: importance of correct Hoxa5 expression for the proper specification of the axial skeleton. Dev Dyn 1998, 212(1):141-56.

51. Sauter CN, McDermid RL, Weinberg AL, Greco TL, Xu X, Murdoch FE, Fritsch MK: Differentiation of murine embryonic stem cells induces progesterone receptor gene expression. Exp Cell Res 2005, 311(2):251-64

52. McCampbell AS, Walker CL, Broaddus RR, Cook JD, Davies PJ: Developmental reprogramming of IGF signaling and susceptibility to endometrial hyperplasia in the rat. Lab Invest 2008, 88(6):615-26.

53. Mason HR, Lake AC, Wubben JE, Nowak RA, Castellot JJ Jr: The growth arrest-specific gene CCN5 is deficient in human leiomyomas and inhibits the proliferation and motility of cultured human uterine smooth muscle cells. Mol Hum Reprod 2004, 10(3):181-7.

doi:10.1186/1750-1172-6-32

Cite this article as: Rall et al:: A combination of transcriptome and methylation analyses reveals embryologically-relevant candidate genes in MRKH patients. Orphanet Journal of Rare Diseases 2011 6:32.

\section{Submit your next manuscript to BioMed Central and take full advantage of:}

- Convenient online submission

- Thorough peer review

- No space constraints or color figure charges

- Immediate publication on acceptance

- Inclusion in PubMed, CAS, Scopus and Google Scholar

- Research which is freely available for redistribution

Submit your manuscript at www.biomedcentral.com/submit
C Biomed Central 